\title{
Studi Mekanisme Kerusakan Tube Reformer Pada Industri Petrokimia
}

\author{
Novielly ${ }^{1}$, Nizhamul Latif ${ }^{2}$, Lukman Noerochim ${ }^{1}$, Budi Agung Kurniawan ${ }^{1}$ \\ ${ }^{1}$ Jurusan Teknik Material dan Metalurgi, Fakultas Teknologi Industri, Institut Teknologi Sepuluh Nopember (ITS) \\ Jl. Arief Rahman Hakim, Surabaya 60111 Indonesia \\ ${ }^{2}$ Badan Pengkajian dan Penerapan Teknologi, Kawasan Puspiptek, Serpong, Tangerang Selatan \\ e-mail : lukman@mat-eng.its.ac.id
}

\begin{abstract}
Abstrak- Reformer biasanya dipakai pada industri Petrokimia untuk menghasilkan hidrogen. Salah satu permasalahan kerusakan/kegagalan yang terjadi adalah pada bagian Tube reformer yang disebabkan oleh pengoperasian pada pengaruh temperatur tinggi. Kegagalan yang terjadi pada tube reformer yang secara visual yaitu adanya crack pada bagian permukaan OD. Analisis yang akan dilakukan yaitu ada 5 pengujian antara lain SEM, Uji tarik, Uji Kekerasan, Uji Komposisi, dan Metalografi. Didapatkan bahwa kegagalan disebabkan oleh overheating yang menyebabkan terjadinya crack yang terdapat pada batas butir. Dari hasil pengujian metalografi ditemukan adanya void - void dan microcrack. Timbulnya void ini disebabkan oleh overheating dan menyebabkan nilai hardness yang tinggi, nilai hardness yang tinggi juga didukung oleh hasil dari EDX, hasil EDX menunjukkan adanya unsur kromium yang tinggi sehingga material menjadi getas. Void yang terdapat pada material HP modified mempengaruhi hasil dari tensile dikarenakan void membuat nilai tensile menjadi rendah. Dari hasil Uji komposisi didapatkan bahwa terdapat unsur yang tidak sesuai seperti Sulfur dan Pospor yang dapat menurunkan sifat dari ketahanan pada temperature tinggi.
\end{abstract}

Kata Kunci- reformer tube, Hp Modified, crack, creep

\section{PENDAHULUAN}

$\mathrm{D}$ ALAM perkembangan teknologi ini juga dipengaruhi oleh bahan bakar dan gas. Contohnya pada industri Petrokimia. Petrokimia sendiri adalah bahan kimia apapun yang diperoleh dari bahan bakar fosil atau didapat dari gas alam. Bahan bakar fosil yang dimaksud merupakan fosil yang telah dipurifikasi seperti metana, propana, butana, bensin, minyak tanah, bahan bakar diesel, bahan bakar pesawat, dan juga termasuk berbagai bahan kimia untuk pertanian seperti pestisida, herbisida, dan pupuk, serta bahanbahan seperti plastik, aspal, dan serat buatan. Industri petrokimia adalah industri yang berkembang berdasarkan suatu pola yang mengkaitkan suatu produk-produk industri minyak bumi yang tersedia, dengan kebutuhan masarakat akan bahan kimia atau bahan konsumsi dalam kehidupan seharihari. Contoh produk-produk industri petrokimia hulu antara lain metanol, etilen, propilen, butadiena, benzena, toluena, xilena, Fuel Coproducts, Pyrolisis Gasoline, Pyrolisis Fuel Oil, dan campuran C4

Reformer biasanya dipakai pada industri Petrokimia. Reformer ini berfungsi untuk memecahkan gas alam seperti metana dengan steam yang nantinya akan meproduksi Amonia, Metanol, Karbon Monoksida, dan hidrogen. Contohnya adalah mereaksikan gas alam (metana) dengan uap air pada temperatur dan tekanan tertentu. Terdapat beberapa variabel yang perlu diperhatikan dalam reformer yaitu temperatur, tekanan, dan juga perbandingan antara gas alam yang masuk dengan steam [1]. Penggunaan temperatur pada Reformer diantara $700{ }^{\circ} \mathrm{C}-900{ }^{\circ} \mathrm{C}$.

HP Modified Alloys biasanya digunakan pada ethylene pyrolysis tubing, steam methane reformer tubing [2]. Paduan ini mempunyai struktur austenitic dan kandungan 25 hingga $70 \%$ nikel dan 10 hingga 26\% Kromium. Dapat bekerja pada temperatur $2100^{\circ} \mathrm{F}$ dikarenakan tidak ada fasa getas pada paduannya ini selan itu pada paduan ini mempunyai sifat yang baik pada pengelasa. Kelompok yang masuk pada paduan ini adalah HP [3]

Pada suatu industri petrokimia, Tube reformer yang sudah beroperasi selama 16 tahun mengalami kegagalan atau kerusakan pada bagian Tube reformer yang berfungsi sebagai pengaliran gas alam dan steam. Terjadi kegagalan pada permukaan tube reformer, jenis kegagalan yang terjadi adalah adanya retak pada bagian luar permukaan tube reformer. Tujuan dari penelitian ini adalah menganalisis penyebab dari kegagalan tube reformer, dan menganalisis mekanisme terjadinya kegagalan pada tube reformer.

\section{METODOLOGI PENELITIAN}

\section{A. Preparasi Spesimen}

Pengamatan visual ini yaitu dengan melihat kondisi pipa pada bagian yang mengalami kegagalan sehingga dapat diketahui kondisi awal dari Tube reformer yang nantinya akan mempermudah tahap analisis yang dilakukan selanjutnya. Terdapat 2 pipa yang akan dianalisis yaitu tube A dan tube B. Tube A adalah tube yang terdapat crack dan terletak dekat dengan burner. Tube B adalah tube yang terletak dibawah jauh dengan burner.

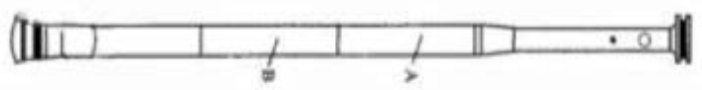

Gambar 1. Pipa tube reformer

Tabel 1. Data awal tube reformer

\begin{tabular}{ll}
\multicolumn{2}{c}{ Tabel 1. Data awal tube reformer } \\
\hline \hline Tipe Tube & $\begin{array}{l}\text { Tubr-35Ni NbTi } \\
\text { 23C Modified } \\
\text { Waktu Beroperasi }\end{array}$ \\
Dimensi & $114 \mathrm{~mm}(\mathrm{ID}) / 123 \mathrm{~mm}(\mathrm{OD})$ \\
Ketebalan & $99 \mathrm{~mm}$
\end{tabular}




\begin{tabular}{ll}
\hline \hline Temperatur Desain & $887^{\circ} \mathrm{C}$ \\
Tekanan Desain & $38 \mathrm{bar}$ \\
Temperatur Operasi & $900^{\circ} \mathrm{C}$ \\
Tekanan Operasi & $33 \mathrm{bar}$ \\
\hline
\end{tabular}

\section{B. Preparasi Metallografi}

Dengan metallografi maka dapat mengetahui dan mempelajari ketidaksempunaan yang terdapat dalam material, seperti fasa, butir, jarak atom, dislokasi yang menyebabkan kegagalan pada tube reformer. Tipe mesin yang digunakan Mikroskop Optik Olympus BX51M Preparasi spesimen melibatkan proses grinding dan polishing. Etsa yang digunakan untuk preparasi metallografi ini adalah dengan etsa kalling $5 \mathrm{gr} \mathrm{CuCl}{ }_{2}+100 \mathrm{ml} \mathrm{HCl}+100 \mathrm{ml}$ ethanol selama 5 detik tahap selanjutnya adalah membersihkan dengan etanol dan dilap dengan tisu.

\section{Pengujian Hardness}

Pengujian ini bertujuan mendapatkan nilai kekerasan dari tube reformer dan hasilnya dibandingkan dengan oleh nilai kekerasan bdata yang sudah ada. Metode Vickers mengacu pada Standar ASTM E92 menggunakan indentor diamond pyramid yang, adapun besar beban $30 \mathrm{~kg}$ selama 10 detik. Tipe mesin yang digunakan untuk pengujian hardness adalah Vickers HBRV 187.5A

\section{Pengujian Tensile}

Dengan pengujian tarik maka setelah itu data dibandingkan kekuatan tarik hasil dari pengujian pada tube reformer dengan spesifikasi kekuatan tarik yang sudah ada, berdasarkan standard ASTM E8. Pengujian uji tarik digunakan untuk mengukur ketahanan suatu material terhadap gaya statis yang diberikan secara lambat. Tipe mesin yang digunakan untuk pengujian tensile adalah Mesin Uji tarik Shimadzu AGS10kNG.

\section{E. Pengujian Spektrometer}

Pengujian ini bertujuan untuk mengetahui unsur - unsur yang terdapat pada HP modified sehingga dapat dibandingkan dengan standard. Mesin yang digunakan untuk uji komposisi adalah Mesin Uji Komposisi PMI-Master pro

\section{F. Pengujian SEM \& EDX}

Pengujian SEM EDX untuk mengetahui struktur material dalam skala mikro pada sampel A dan B. Fasa- fasa yang ada pada material yang akan diuji dan untuk mengetahui unsur yang ada pada material tersebut. Mesin uii yang digunakan Mesin SEM8EDX 10 JEOL JSM-6390A.

\section{HASIL DAN PEMBAHASAN}

\section{A. Hasil Metallografi}

Pengujian metalografi dilakukan dengan perbesaran 100x, 200x setiap spesimen. Dan etsa yang digunakan untuk sampel ini adalah kalling. Bagian yang akan ditembak untuk melihat struktur mikronya adalah pada bagian dekat OD, dan dekat ID. Berikut adalah gambar hasil menggunakan etsa kalling:
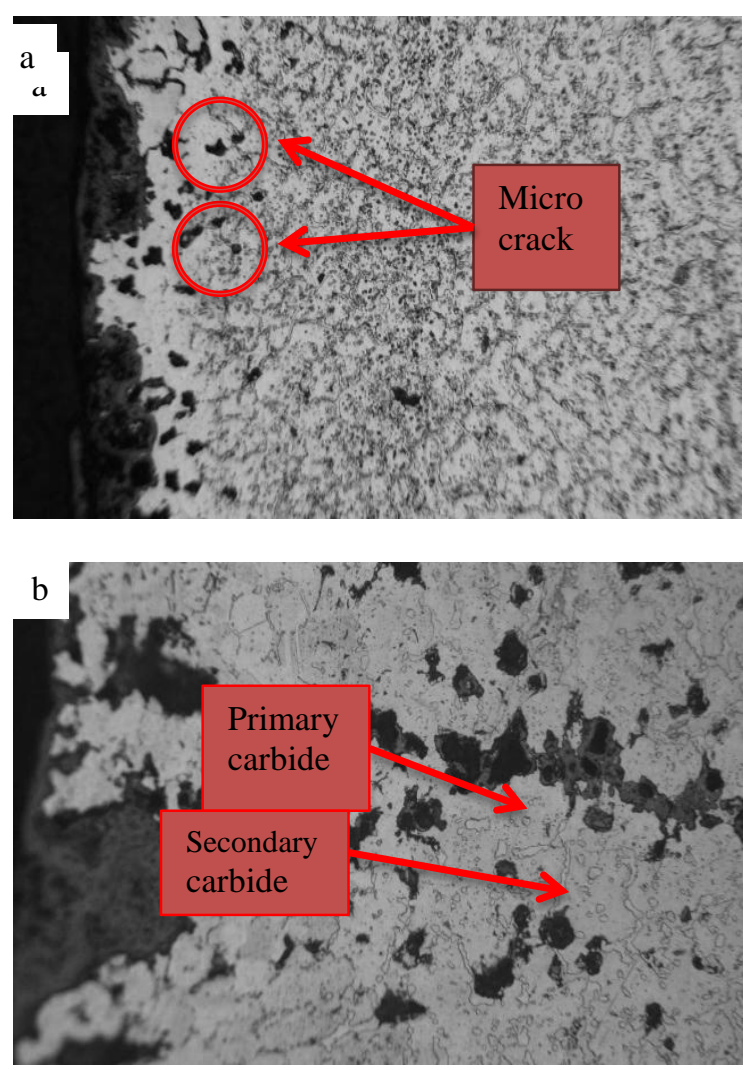

Gambar 2. Foto Mikrostruktur perbesaran 100x(a), 200x(a) sampel A bagian dekat OD
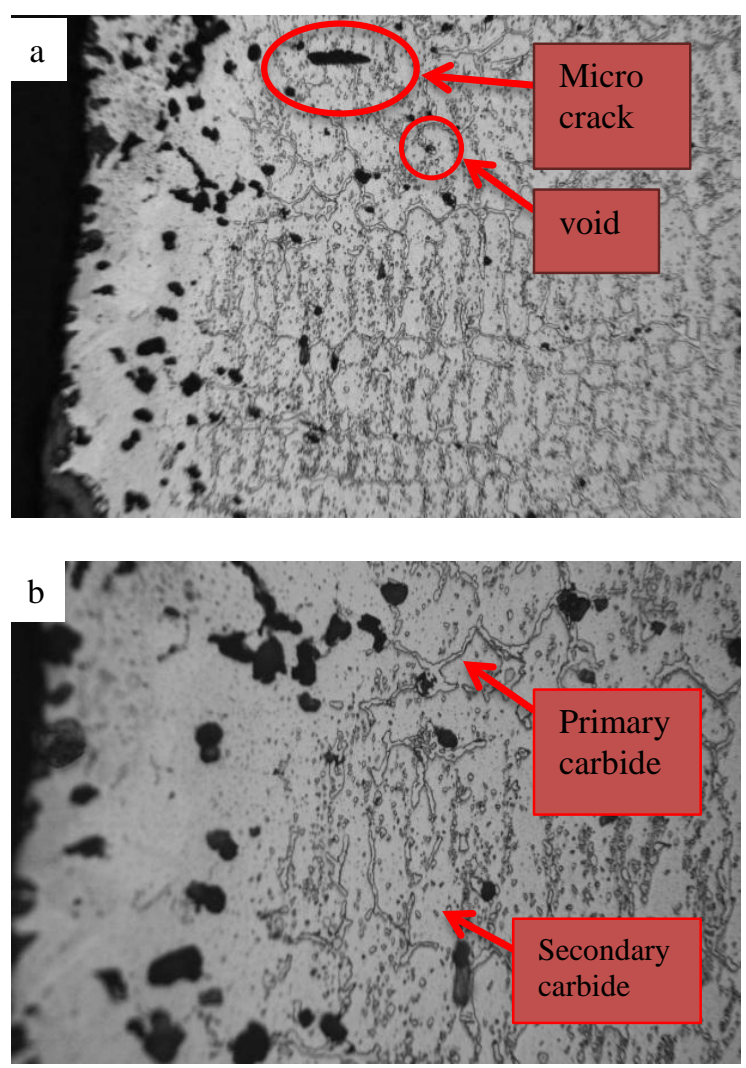

Gambar 3. Foto Mikrostruktur perbesaran 100x(a), 200x(a) sampel B bagian dekat OD 

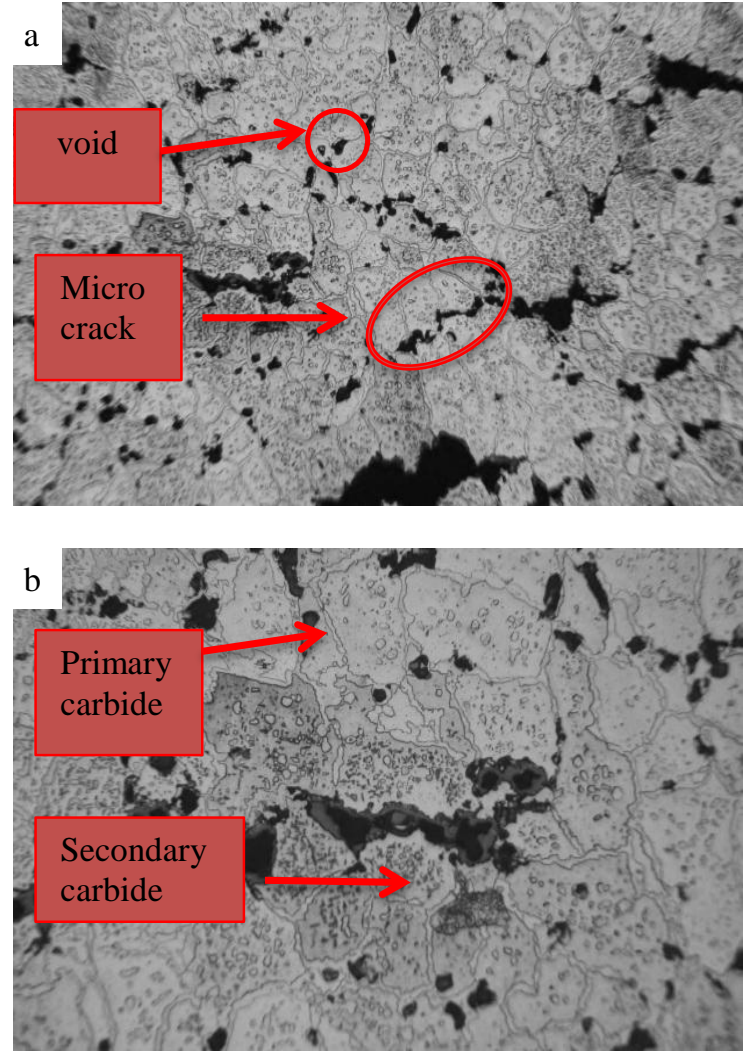

Gambar 4. Foto Mikrostruktur perbesaran 100x(a), 200x(a) sampel A bagian dekat ID
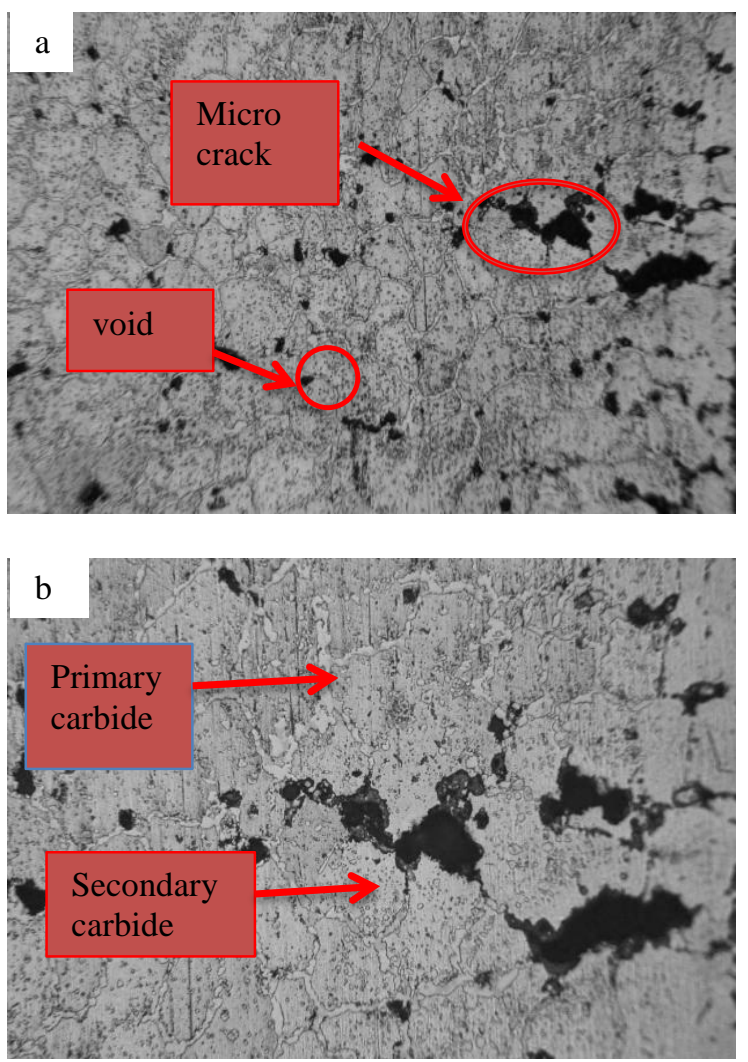

Gambar 5. Foto Mikrostruktur perbesaran 100x(a), 200x(a) sampel B bagian dekat ID

Perbandingan sampel A dan sampel B terlihat jelas pada jumlah void, microcrack, creep cracking. Sampel A memiliki void yang lebih sedikit dibanding sampel $\mathrm{B}$, hal ini disebabkan oleh void- void yang terdapat pada sampel A telah bersatu menjadi microcrack ditunjukkan pada gambar 2(a),3(a),4(a),5(a). Void yang terjadi pada sampel A dan sampel B disebabkan oleh proses aging, terdapat enam tahap mekanisme terjadinya void [4]. Void ini dipengaruhi oleh primary carbide dan secondary carbide ditunjukkan pada gambar 2(b),3(b),4(b),5(b). Apabila semakin halus partikel secondary carbides ini, maka semakin besar kekuatan creep [5]. Seiring lamanya pemakaian dan/atau temperatur layanan meningkat, maka karbida sekunder menyebar dan menjadi kasar. Dengan hilangnya karbida sekunder dari fasa austenit maka kekuatan creep berkurang. Jenis patahan yang terjadi adalah jenis patahan intergranular disebabkan patahan yang terjadi pada bagian batas butir. Pengaruh munculnya void ini dipengaruhi oleh temperatur. apabila tabung yang overheated maka akan mempengaruhi life time dari tube. Ini umumnya tidak menyebabkan kegagalan segera tapi pasti akan menghasilkan pengurangan dalam hidup [6]

\section{B. Hasil Pengujian Kekerasan}

\begin{tabular}{ccccc}
\multicolumn{5}{c}{ Tabel 2. Hasil pengujian Hardness } \\
\hline \hline POSISI & \multicolumn{3}{c}{ Sampel A (VHN) } & $\begin{array}{c}\text { Rata - Rata } \\
\text { (VHN) }\end{array}$ \\
\hline Luar & 191 & 189 & 192 & 190 \\
Tengah & 178 & 173 & 175 & 175,3 \\
Dalam & 188 & 187 & 187 & 187,3 \\
& \multicolumn{5}{c}{ Sampel B (VHN) } \\
POSISI & 189 & 185 & 188 & 187 \\
Luar & 159 & 160 & 158 & 159 \\
Tengah & 170 & 167 & 165 & 167,3 \\
Dalam & 170 &
\end{tabular}

Pada pengujian kekerasan dilakukan 3 kali penjejakan tiap daerah yaitu pada bagian luar, tengah, dan dalam. Pada bagian luar sampel A dan sampel B memiliki kekerasan diatas dari literature yaitu 170 BHN sama dengan 179 VHN. Terdapat nilai kekerasan yang tinggi dan juga lebih rendah dibandingkan dengan literatur. Kekerasan tube katalis tersebut melampaui nilai kekerasan spesifikasi dari tube HP Modified Nb-Ti akibat dari adanya pertumbuhan dari presipitasi karbida. Kekerasan yang lebih rendah disebabkan oleh pengeroposan yang terjadi pada permukaan yang mengalami creep.

\section{Hasil Pengujian SEM \& EDX}

Berikut adalah Hasil dari pengujian SEM sampel A dan B : 


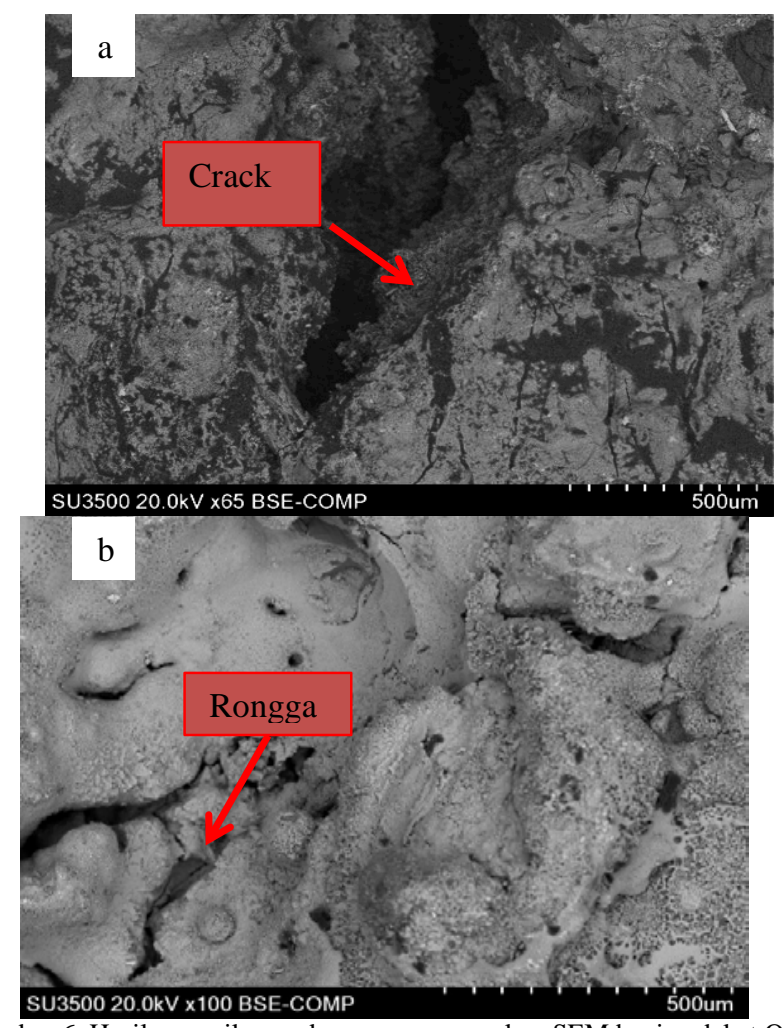

Gambar 6. Hasil pemeriksaan dengan menggunakan SEM bagian dekat OD tube A (a), bagian dekat ID tube B (b)

Berikut adalah gambar hasil dari EDX pada spesimen A dan B.

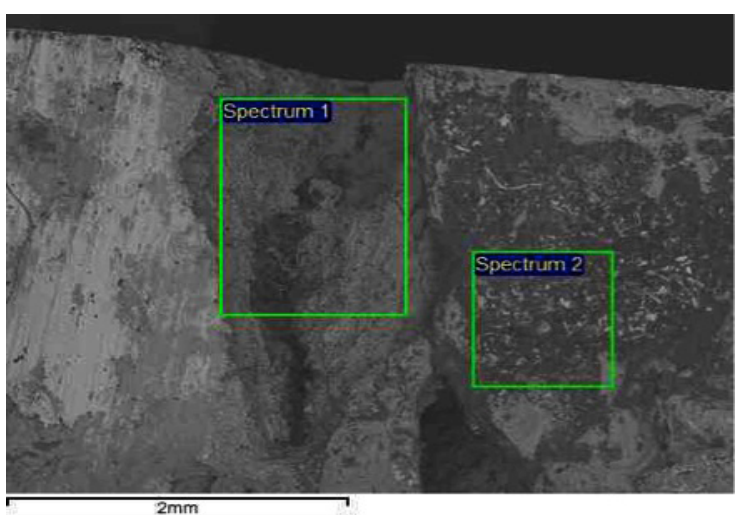

Gambar 7. Lokasi pemeriksaan EDX sampel A1, A2

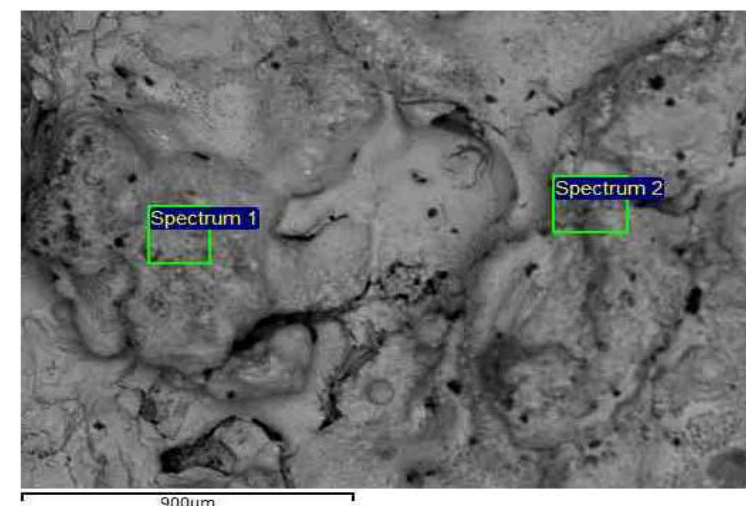

Gambar 8. Lokasi pemeriksaan EDX sampel B1 dan B2
Tabel 3. Hasil pengujian EDX

\begin{tabular}{ccccc}
\hline \hline & & Titik & & \\
Unsur (\%) & A Spektrum & A Spektrum & B Spektrum & B Spektrum \\
& 1 & 2 & 1 & 2 \\
\hline $\mathrm{Fe}$ & 35.5 & 9.15 & 18.56 & 17.97 \\
$\mathrm{Cr}$ & 33.03 & 10.31 & 13.56 & 13.56 \\
$\mathrm{Mn}$ & 14.03 & 12.32 & 11.45 & 11.76 \\
$\mathrm{O}$ & 5.03 & 11.64 & 9.31 & 9.3 \\
$\mathrm{C}$ & 1.07 & 13.94 & 5.65 & 5.49 \\
$\mathrm{Ni}$ & 3.88 & 3.01 & 6.54 & 6.87 \\
$\mathrm{Ca}$ & & 23.36 & 2.68 & 2.7 \\
$\mathrm{Al}$ & 1.84 & 3.54 & 1.28 & 2.58 \\
$\mathrm{Na}$ & 2.98 & & 2.31 & 1.34 \\
$\mathrm{Si}$ & 2.5 & 5.12 & 4.35 & \\
$\mathrm{Mg}$ & & 3.12 & & 0.54 \\
$\mathrm{Ti}$ & & 5.56 & 24.31 & 24.35 \\
$\mathrm{~S}$ & & 0.93 & & \\
\hline \hline
\end{tabular}

Dari hasil SEM pada sampel A terdapat adanya crack dan juga dapat dilihat terdapat adanya lubang - lubang kecil yang nantinya dapat menyebabkan adanya crack. Pada sampel B terdapat adanya rongga- rongga dan lubang - lubang pada permukaan. Penyebab terlihatnya lubang - lubang ini dikarenakan oleh void - void bergabung sehingga menjadi microcrack [7].

Pada sampel A Spektrum 1 yaitu Kromium Karbida sehingga kemungkinan unsur ini yang menyebabkan nilai kekerasan yang tinggi sehingga material menjadi getas. Pada spectrum 2 (bagian dekat retakan) sampe A unsur tertinggi yaitu $\mathrm{Ca}$, $\mathrm{Ca}$ ini adalah unsur pengotor dan begitu pula terdapat unsur $\mathrm{C}$ yang tinggi sehingga dapat membuat nilai kekerasan suatu material menjadi lebih tinggi dibandingkan dengan literature. Selain itu terdapat unsur S yang mempunyai nilai yang tinggi sehingga dapat membuat material menjadi lebih getas

Pada Sampel B titik Spektrum 1,2 mempunyai nilai komposisi yang tidak terlalu berbeda. Terdapat nilai tertinggi Ti dimana Ti berfungsi untuk mencegahnya terjadi karbida Cr.

\section{Hasil Pengujian Tensile}

Tabel 4. Hasil pengujian Tensile

\begin{tabular}{ccccccc}
\hline \hline Sampel & \multicolumn{2}{c}{ Dimensi (mm) } & $\mathrm{A}_{0}$ & $\mathrm{~F}$ & $\begin{array}{c}\sigma \\
(\mathrm{UTS})\end{array}$ & $\varepsilon$ \\
& Lebar & Tebal & $\left(\mathrm{mm}^{2}\right)$ & $(\mathrm{kN})$ & $\begin{array}{c}\left(\mathrm{N} / \mathrm{mm}^{2}\right) / \\
(\mathrm{MPa})\end{array}$ & $(\%)$ \\
\hline $\mathrm{A}$ & 18,93 & 8,85 & 167,53 & 60 & 358 & 4 \\
$\mathrm{~B}$ & 18,85 & 9,10 & 171,54 & 53 & 309 & 4 \\
\hline \hline
\end{tabular}

Dari pengujian tarik yang telah dilakukan pada sampel A dan B didapatkan nilai 358 Mpa dan 309 Mpa. Nilai yang didapatkan ini berada jauh dibawah dibandingkan dengan data teknis yaitu 450 Mpa. Kemampuan menerima beban/ tegangan yang menurun ini disebabkan oleh material yang diakibatkan oleh creep yang terjadi pada material HP Modified Nb-Ti. Sehingga menyebabkan material mengalami penuruan kemampuannya untuk menahan beban dan menyebabkan crack. Pada kondisi creep, creep rate akan meningkat apabila adanya kenaikan pada temperatur, maka umur hidup dari suatu material akan menurun apabila temperatur dinaikkan [1]. 


\section{E. Hasil Spektrometer}

Berikut adalah tabel hasil dari pengujian komposisi yang dilakukan pada pipa:

\begin{tabular}{lc}
\multicolumn{2}{c}{ Tabel 5. Hasil pengujian Spektrometer } \\
\hline \hline Unsur & $\begin{array}{c}\text { HP-Modified } \\
\text { (\%) }\end{array}$ \\
\hline $\mathrm{C}$ & 0.515 \\
$\mathrm{Ni}$ & 35.2 \\
$\mathrm{Cr}$ & 25.3 \\
$\mathrm{Nb}$ & 0.944 \\
$\mathrm{Ti}$ & 0.159 \\
$\mathrm{Si}$ & 1.03 \\
$\mathrm{Mn}$ & 0.594 \\
$\mathrm{~W}$ & 0.116 \\
$\mathrm{~V}$ & 0.172 \\
$\mathrm{Co}$ & 0.0958 \\
$\mathrm{Mo}$ & 0.11 \\
$\mathrm{P}$ & 0.063 \\
$\mathrm{~S}$ & 0.0594 \\
\hline \hline
\end{tabular}

Dari hasil pengujian Komposisi, hampir semua unsur dalam material $\mathrm{HP}+\mathrm{NB} \mathrm{Ti}$ ini memiliki komposisi yang sesuai dengan data teknis. Unsur yang tidak sesuai apabila dibandingkan dengan data teknis yaitu unsur P, S. Unsur P dan $\mathrm{S}$ memiliki nilai yang lebih besar dibandingkan nilai yang maksimal yang sudah ditetapkan.

Dapat diketahui bahwa adanya unsur Sulfur adalah suatu zat yang biasanya terdapat pada baja tetapi keberadaanya tidak begitu diinginkan karena bersifat rapuh [8], dan juga dapat menyebabkan material menjadi getas sedangkan Phospor sendiri dapat menyebabkan elastisitas dan tahan terhadap benturan menurun. Sifat dari Sulfur dan Phospor yang dapat mempengaruhi tube reformer adalah dapat mengurangi ketahanan terhadap kondisi temperatur yang tinggi. Pengurangan disebabkan oleh creep yang dapat dilihat dari hasil metalografi bahwa adanya void, microcrack sehingga mengalami keroposan yang dapat mengalami penurunan pada hasil kekuatan

\section{KESIMPULAN}

Dari pengujian dan analisa yang telah dilakukan diperoleh kesimpulan bahwa :

1. Penyebab crack disebabkan oleh overheating sehingga terjadi pengeroposan yang diinisiasi oleh void -void pada strukturmikro, void - void bergabung dan menjadi mikro crack dan temperature yang lebih tinggi dibandingkan dengan temperature yang telah di desain.

2. Mekanisme kegagalan pada tube reformer diawali dengan overheating yang menyebabkan munculnya void pada struktur mikro dan adanya mikrocrack selain itu overheating menyebabkan adanya presipitasi karbida sehingga material menjadi getas. Dikarenakan tegangan yang terus menerus sesuai dengan tegangan operasional maka material tidak lagi dapat menahan beban dan menyebabkan material menjadi gagal

\section{DAFTAR PUSTAKA}

[1] Schmidt, Clemens Group. 2010. Material Selection for Primary Reformer Adding value to your asset. Bahrain. SC

[2] Shariat,M.H. 2003. In advance Creep Failure of H.P Modified Reformer Tubes in an Ammonia Plant. Shiraz. JCSE

[3] _ Heat and Corrosion Resistant Castings; Their Engineering. Publication No266

[4] Hatta, Ilham. 2002. Analisis Kerusakan Pipa Baja HP- Modified yang Digunakan Pada Hydrogent Plant. Tangerang; BPPT

[5] Hawkins, Gerrad. 2013. Steam Reforming: Tube Design. Phoenix. GBH Enterprises Ltd

[6] Luiz, Tito. 2006. Reformer Furnaces: Materials, Damage Mechanisms, and Assessment. Brazil. Metallurgical Consulting Services Ltd.

[7] Shariat,M.H. 2003. In advance Creep Failure of H.P Modified Reformer Tubes in an Ammonia Plant. Shiraz. JCSE

[8] Budianto, Anwar. 2009. PENGAMATAN STRUKTUR MIKRO PADA KOROSI ANTAR BUTIR DARI MATERIAL BAJA TAHAN KARAT AUSTENITIK SETELAH MENGALAMI PROSES PEMANASAN. Yogyakarta. Pusat Teknologi Akselerator dan Proses Bahan. 